\title{
The Structural Integrity of Affordable Thick-Section Fiber Composites
}

Steven J. DeTeresa

June 1999

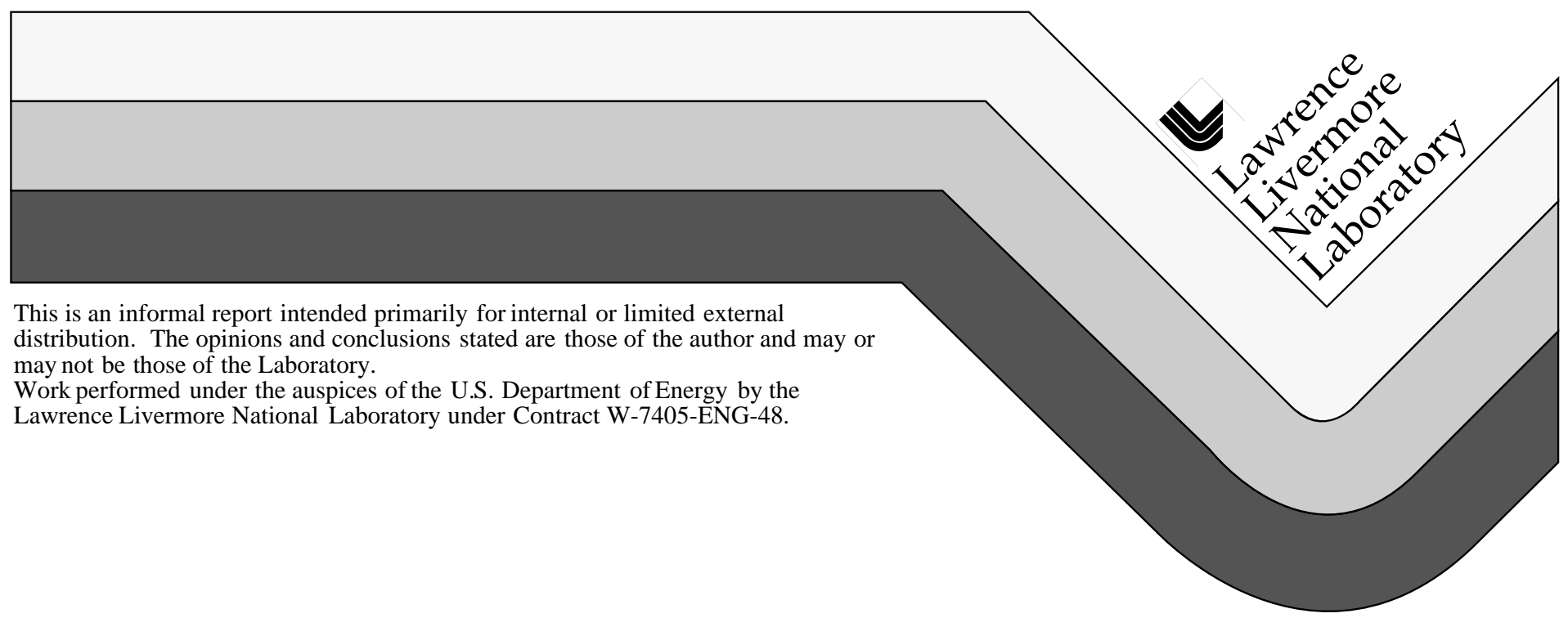




\section{DISCLAIMER}

This document was prepared as an account of work sponsored by an agency of the United States Government. Neither the United States Government nor the University of California nor any of their employees, makes any warranty, express or implied, or assumes any legal liability or responsibility for the accuracy, completeness, or usefulness of any information, apparatus, product, or process disclosed, or represents that its use would not infringe privately owned rights. Reference herein to any specific commercial product, process, or service by trade name, trademark, manufacturer, or otherwise, does not necessarily constitute or imply its endorsement, recommendation, or favoring by the United States Government or the University of California. The views and opinions of authors expressed herein do not necessarily state or reflect those of the United States Government or the University of California, and shall not be used for advertising or product endorsement purposes.

This report has been reproduced directly from the best available copy.

Available to DOE and DOE contractors from the Office of Scientific and Technical Information P.O. Box 62, Oak Ridge, TN 37831

Prices available from (423) 576-8401

Available to the public from the National Technical Information Service

U.S. Department of Commerce 5285 Port Royal Rd., Springfield, VA 22161 


\title{
The Structural Integrity of Affordable Thick-Section Fiber Composites
}

\author{
Steven J. DeTeresa \\ University of California \\ Lawrence Livermore National Laboratory \\ Mechanical Engineering Department \\ 7000 East Avenue \\ MS L-342 \\ Livermore, CA 94550 \\ (925) 422-6466 \\ (925) 422-2438 \\ deteresa1@1lnl.gov
}

Contract Number: N00014-96-F-0422

ONR Program Officer: Dr. Y. D. S. Rajapakse

\section{Long-Term Research Objectives:}

Advance the understanding of the mechanics of polymers and polymer composites. Develop predictive capabilities as well as experimental characterization and validation tools for the mechanical behavior of these materials. Further develop our knowledge of structure-mechanical property relationships for this class of materials.

\section{ONR Science \& Technology Objectives:}

To determine design criteria and reliability of economical thick-section fiber composites and sandwich core materials. To critically evaluate and then recommend or develop failure models suitable for numerical analyses.

\section{Approach:}

Develop novel experimental tools and use them to characterize the multiaxial failure and fatigue behavior of materials for thick-section fiber composite structures. These tools include capabilities for applying well-defined biaxial and triaxial stress states. These experiments are carefully chosen to provide results that can be used for discriminating evaluation of predictive failure models.

\section{Science \& Technology Completed:}

Additional results were obtained this year for the study of fatigue response of thick-section, laminated fiber composites under interlaminar stresses. Using a new experimental technique, we 
have demonstrated that interlaminar shear fatigue lifetime is greatly enhanced by the superposition of through-thickness compression stress. The fatigue lifetime curve is well described by a single characteristic curve that is simply normalized to static strength. We have found that this result also holds true for performance degradation due to moisture absorption. Relatively low levels of moisture (less than $1 \mathrm{wt} . \%$ ) were found to significantly reduce the static strength and fatigue lifetimes of a composite system at elevated temperature. When fatigue data is normalized for the static strength reduction, the single characteristic curve obtained from measurements of dry materials adequately predicts the performance degradation due to moisture absorption.

We have completed a study of the effect of superimposed pressure on the longitudinal and transverse compression strengths of two composite material systems. These experiments were performed for the purpose of critically evaluating proposed three-dimensional failure criteria for thick-section composites. While no single failure criterion predicted the observed relationships between compression strength and pressure, we found that a stress-based criterion ${ }^{1}$ that accounts for fiber- and matrix-dominated failure separately did the best overall job of predicting at least the trends of strength change with pressure. The popular tensor polynomial theory was found to be the least accurate in predicting experimentally observed results. It was also found that this failure theory, as well as the commonly used maximum strain and stress criteria, predicted failure under pure superimposed hydrostatic pressure. None of the experimental results indicated that this mode of failure occurred in either of the two materials examined.

A study of the failure of low-density materials for cores in sandwich structures is just beginning. One goal is characterize the failure envelopes under various conditions of combined stress, temperature, and environment. Preliminary results from biaxial tests indicate that a simple twoparameter, pressure-dependent yield criterion can predict the failure envelope for combined through-thickness shear and normal stresses.

\section{Impact/Navy Relevance:}

The significance of the study of failure and fatigue of thick-section composites under combined interlaminar stresses is the potential for greatly reducing the cost of characterizing the reliability of these materials. Although further study of other material systems is needed, these first results indicate that a significant amount of fatigue lifetime performance may be predicted using a single fatigue curve with the static strengths for different temperatures and moisture absorption levels. Furthermore, the finding that through-thickness compression can enhance both strength and fatigue life can be exploited in structural design, especially at joints.

The studies to evaluate failure criteria using tests under superimposed hydrostatic pressure will help guide the selection of rational theories for thick-section composites. The selection of a single, validated failure model is still one of the most significant outstanding problem in the discipline of fiber composite materials. Our results to date have already revealed the more successful failure models for a fiber composite lamina. 


\section{Planned Research Efforts:}

During the next year, further characterization of the failure and fatigue of thick-section composites under combined stresses will be made to determine the generality of the observations made to date. These studies will incorporate the low-cost materials, both fiber composite skins and low-density cores, currently used in ship sandwich structures. Results will be used to continue critical evaluation of failure models. The end results will be pertinent data for reliability of Naval composite materials and selected failure criteria for numerical simulations and design studies of ship structures.

\section{Technology Transfer:}

We continue to maintain working relationships with DoD laboratories including the NSWC facilities at Carderock, MD and Dahlgren, VA, as well as the Army Research Laboratory at Aberdeen, MD and the Advanced Research and Engineering Development Center at Picatinny, NJ. Significant results are reported annually at workshops held at several of these facilities. We also have significant interaction with the USCAR consortium, which seeks to provide the basic research and build the confidence required to use fiber composites in primary automotive structures.

\section{References:}

1. Christensen, R. M., "The Numbers of Elastic Properties and Failure Parameters for Fiber Composites," Trans. ASME (1998) 120 pp. 110-113.

\section{Other Sponsored Science \& Technology:}

1. “Advanced Composites Technology," Joint DoD/DOE Advanced Munitions Technology Program, \$400K/yr. 10/98 to 9/03. Technology development for application of thick-section fiber composites to new munitions concepts and designs.

2. "Simulated Aging of High Explosives," DOE Enhanced Surveillance Program, \$350K/yr. $10 / 98$ to $9 / 01$. Characterize fundamental aging mechanisms in plastic-bonded explosives and develop methodology to produce aged material for performance studies.

3. "Simulation of Fiber Composite Crashworthy Structures for Automotive Applications," DOE Office of Transportation Technologies. \$500/yr. 10/98 to 9/00. Characterize dynamic properties and failure mechanisms in tubular composite structures and develop computer simulation tools for energy absorption processes.

4. "Stress-Rupture Lifetimes of T700SC Carbon Fiber," Toray Industries, Inc. \$100K 10/97 to 10/99. Determine stress-rupture lifetimes for unidirectional carbon fiber composites.

\section{Visual:}

(Sent as separate file) 


\section{Productivity}

Publications:

DeTeresa, S. J., Freeman, D. C., and Groves, S. E., "Fatigue and Fracture of Fiber Composites under Combined Interlaminar Stresses," Proceedings, $13^{\text {th }}$ Annual Technical Conference on Composites, American Society for Composites, Baltimore, MD, Sept. 21-23, 1998.

Hoppel, C. P. R. and DeTeresa, S. J., "Effect of Angle-Ply Orientation on

Compression Strength of Composite Laminates," Proceedings, U.S. Army Symposium on Solid Mechanics, Myrtle Beach, S. C. 14 April, 1999.

DeTeresa, S. J., Groves, S. E., and Sanchez, R. J., “Advanced Composites Technology,” Army Research Laboratory Report ARL-CR-424, December, 1998.

Contributing author to "Science and Technology to Defend Our National Interests," Science \& Technology Review, Lawrence Livermore National Laboratory, May (1999).

Presentations:

DeTeresa, S. J., Freeman, D. C., and Groves, S. E., "Fatigue and Fracture of Fiber Composites under Combined Interlaminar Stresses," $13^{\text {th }}$ Annual Technical Conference on Composites, American Society for Composites, Baltimore, MD, Sept. 21-23, 1998.

DeTeresa, S. J., Groves, S. E., Saculla, M. D., and Sanchez, R. E., "Fiber of a Fiber Composite Lamina Under Superimposed Hydrostatic Pressure," Symposium on Multiaxial Fatigue and Deformation: Testing and Prediction, ASTM, Seattle, WA, May 19-20, 1999. 